\title{
Exogenous Introduction of Initiator and Executioner Caspases Result in Different Apoptotic Outcomes
}

\author{
Francesca Anson, Sankaran Thayumanavan ${ }^{\star \star}$ and Jeanne A. Hardy ${ }^{\star \ddagger}$ \\ *Department of Chemistry, "Department of Biomedical Engineering and the ${ }^{\ddagger}$ Center for Bioactive Delivery at \\ the Institute for Applied Life Sciences, University of Massachusetts, Amherst, Massachusetts 01003, United \\ States
}

*hardy@chem.umass.edu

*thai@chem.umass.edu

1. Materials and Instruments $\quad$ S2

2. Additional methods/experimental
I. PEG-PDS random copolymer synthesis $\quad \mathrm{S} 2$

II. PEG-PDS and precursor molecule characterization

ii. PDSMA 1H NMR $\quad$ S3

iii. PEG-PDS polymer 1H NMR S3

$\begin{array}{ll}\text { III. Protein expression and purification } & \text { S4 } \\ \text { i. Casp-3 }\end{array}$

ii. Casp-6 $\quad$ S4

iii. Casp-7 $\quad$ S4

iv. Casp-8

v. Casp-9 S5

IV. Evaluation of caspase solvent exposed cysteines

$\begin{array}{lll}\text { V. Casp-NG formation, characterization and evaluation } & \\ \text { i. Casp-NG protein release and encapsulation comparisons } & \text { S5 }\end{array}$

ii. Casp-NG size evaluation $\quad$ S5

iii. Cy5-Casp labeling, nanogel formation and uptake analysis $\quad$ S5

3. Supplemental Figures

$\begin{array}{lll}\circ & \text { Figure S1. Apoptotic caspase NG encapsulation efficiencies } & \text { S7 }\end{array}$

- Figure S2. Casp-9 $9_{\mathrm{CD}}$ NG encapsulation and release $\quad S 7$

- Figure S3. NG-released caspase activity in lysates workflow S8

- Figure S4. Cy5-apoptotic caspase delivery by flow cytometry S8

- Figure S5. Casp-8 NG delivery S8

- Figure S6. Workflow for apoptosis evaluation using 7-AAD $\quad$ S9

$\circ$ Figure S7. Casp-9 $9_{\mathrm{CD}}$ NG induced cell death S9

- Figure S8. Handcuffed casp-7 PEG-PDS NG S9

- Figure S9. Workflows for evaluating executioner caspase activity in whole/lysed S10

- Figure S10. Executioner caspase activity in cells, with DTT S10

- Figure S11. Executioner caspase activity in cell lysates over time S11

4. Supplemental Scheme

I. Scheme 1. Known caspase-procaspase activation pathways and references $\quad \mathrm{S} 12$

5. Supplemental Tables

I. S1. Kinetic Parameters for caspase variants $\quad \mathrm{S} 13$

II. S2. Casp-3, -7 methods of inhibition S13

III. S3. Summary of apoptotic casp-NG results $\quad$ S13

6. Supplemental References $\quad$ S14 


\section{Materials and Instruments}

Materials and Instruments. All chemicals were purchased from commercial sources, such as Thermo Fisher Scientific and Sigma Aldrich, and used without additional purification or modification. Azobisisobutyronitrile (AIBN) was purchased but was used after purification by recrystallization. 1H NMR spectra were recorded on a $400 \mathrm{MHz}$ Bruker NMR spectrometer using the residual proton resonance of the solvent as the internal standards, chemical shifts are reported in parts per million (ppm). Molecular weight of the polymers were estimated by gel permeation chromatography (GPC) in THF using poly (methyl methacrylate) (PMMA) standards with a refractive index detector. UV-Vis absorption spectra and fluorescence spectra were recorded on a Spectramax M5 spectrophotometer with clear or black 96-well plates, accordingly. Dynamic light scattering (DLS) measurements were performed using a Malvern Nanozetasizer. Thermal denaturation was measured using a CFX Connect Real-Time PCR detection system (BioRad Laboratories Inc.). Microscopy images provided by ZOE Fluorescent Cell Imager (BioRad) and Yokogawa Spinning Disc Confocal Microscope (Nikon) with image workup through ImageJ (FIJI). Flow cytometry experiments executed using BD DUAL LSR Fortessa Laser FACS and data analysis through FlowJo 10.

\section{Additional methods/experimental}

\section{I Synthesis}

2.I.i Random Copolymer synthesis - PEG-PDS random copolymer was synthesized as previously documented using commercially available polyethylene glycol monomethyl ether methacrylate (PEGMA) and synthesized pyridyl disulfide methacrylate (PDSMA) monomers in the presence of AIBN and a commercial RAFT reagent 4-cyano-4[(dodecylsulfanylthiocarbonyl) sulfanyl]pentanoic acid. ${ }^{1}$ Pyridyl disulfide methacrylate (PDSMA) was prepared using a previously reported procedure. ${ }^{2}$ PDSMA (400 mg, $\left.1.56 \mathrm{mmol}\right)$, PEGMA (784 mg, $1.56 \mathrm{mmol}$ ) and RAFT (24 mg, 0.059 $\mathrm{mmol}$ ) reagent were dissolved in $2000 \mu \mathrm{L}$ dry THF in a $10 \mathrm{~mL}$ vial and a catalytic amount of AIBN (1.9 mg, $0.0038 \mathrm{mmol})$ in $200 \mu \mathrm{L}$ dry THF was added to that. The solution was degassed by performing three freeze-pump-thaw cycles with an argon inflow into the reaction. The reaction flask was tightly sealed and placed in a preheated oil bath at $65{ }^{\circ} \mathrm{C}$ with overnight stirring. The next day, the polymerization was quenched by lowering the reaction temperature, and the polymer was purified by dialysis against a mixture of acetone and dichloromethane. Finally, the product was evaporated and dried under high vacuum to get a highly viscous yellow polymer. GPC (THF) Mn: 17.746 kDa, PDI: 1.2. The relative ratios between PEGMA and PDSMA were calculated from ${ }^{1} \mathrm{H}$ NMR considering the integration of peaks corresponding end group methyl of PEGMA at $3.3 \mathrm{ppm}$ and aromatic peak of PDSMA at $8.5 \mathrm{ppm}$ which was found to be PEGMA:PDSMA $=55: 45$. ${ }^{1} \mathrm{H} \mathrm{NMR}(400 \mathrm{MHz}$, $\left.\mathrm{CDCl}_{3}\right) \delta 8.45,7.69,7.28,7.13,4.23,4.08,3.63,3.56,3.05,1.88,1.04,0.90$.

\section{II NMR Characterization}

\section{II.i PDSOH 1H NMR after synthesis and purification}

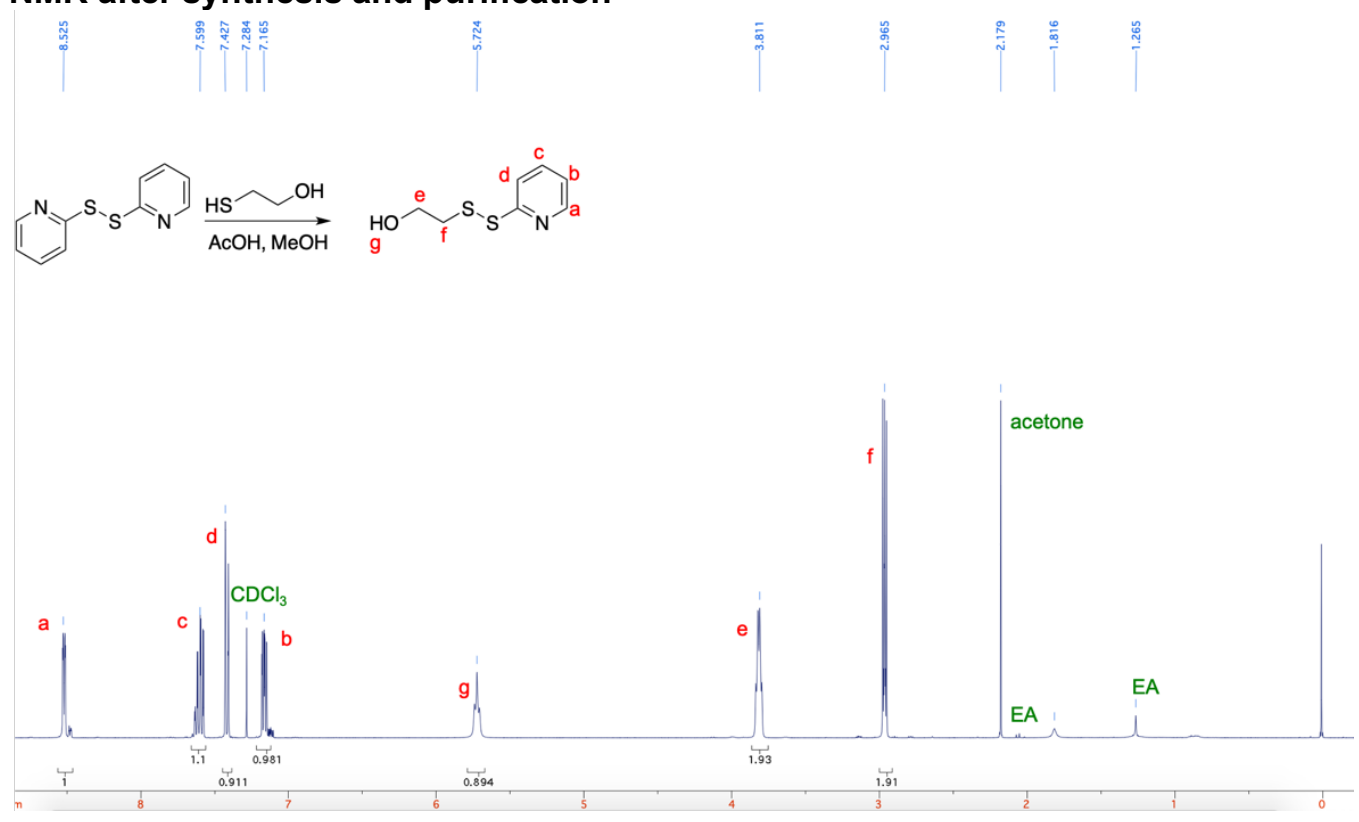


2.II.ii PDSMA 1H NMR after synthesis and purification

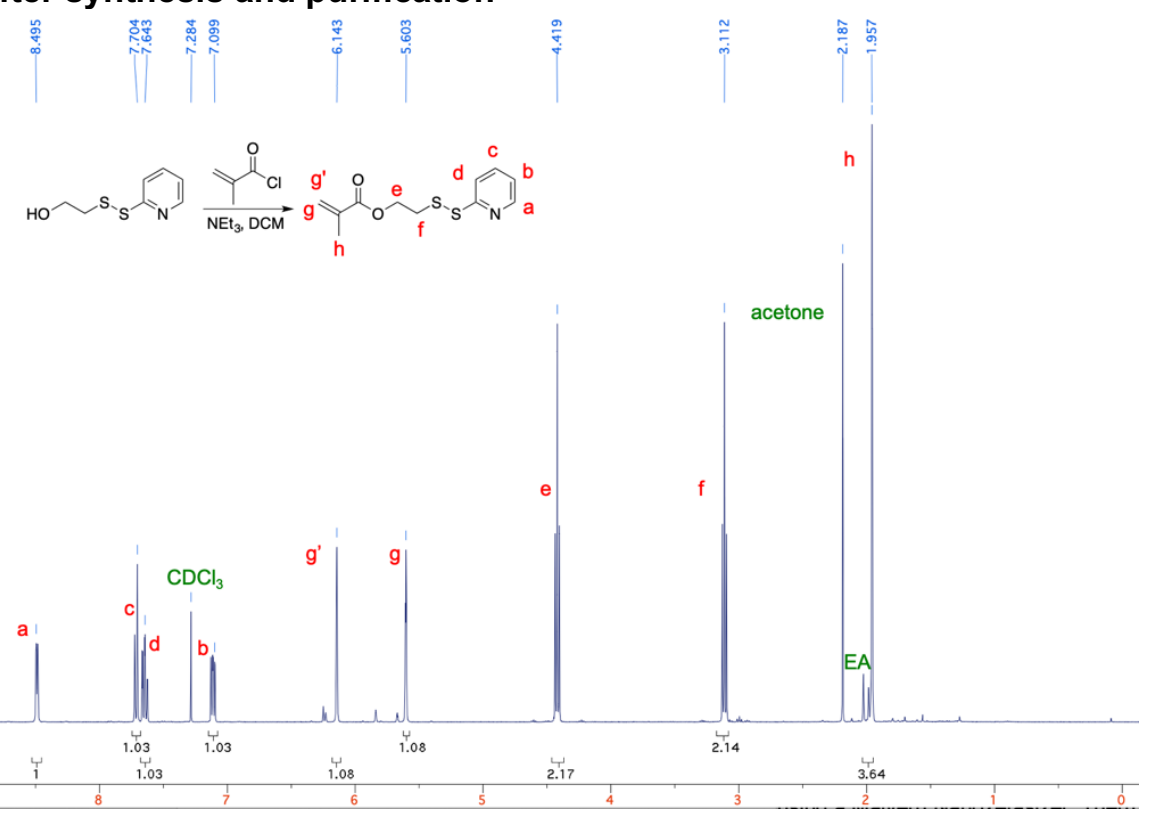

2.II.iii PEG-PDS polymer 1H NMR after synthesis and purification

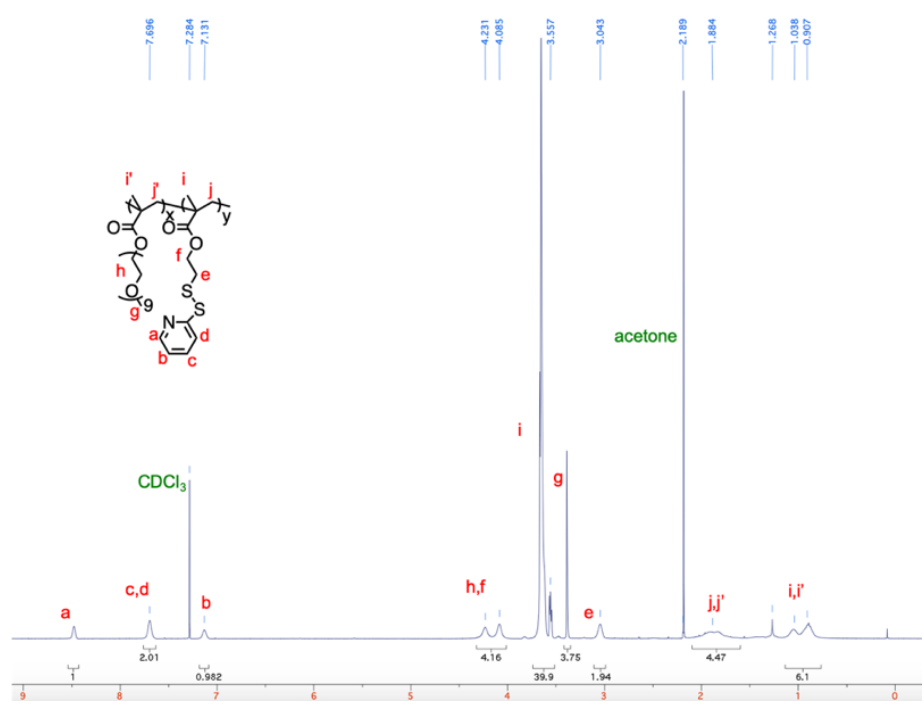




\section{III Protein expression and purification}

2.III.i Casp-3 expression and purification - pET 23b $\mathrm{b}^{3}$ plasmid encoding human WT casp-3 was transformed into BL21(DE3) E.coli cells via electroporation and plated on agar plates containing ampicillin. Single colony cultures were grown in $50 \mathrm{~mL}$ LB media with the corresponding antibiotic at $37^{\circ} \mathrm{C}$ overnight. The following day $8 \mathrm{~L}$ of LB was inoculated with $\sim 5 \mathrm{~mL}$ per $\mathrm{L}$ of the small seed culture and grown at $37^{\circ} \mathrm{C}$ until an $\mathrm{OD}_{600}$ of $\sim 0.6$ was achieved. The incubation temperature was then reduced to $25^{\circ} \mathrm{C}$ and cells were induced with a final concentration of $1 \mathrm{mM}$ isopropyl $\beta$-D-1thiogalactopyranoside (IPTG) and left to express for $\sim 3$ hours. Cells were then harvested via centrifugation for 10 minutes at $5 \mathrm{k}$ RPM and stored at $-80^{\circ} \mathrm{C}$. Cell pellets were thawed and lysed using a microfluidizer (Microfluyidics, Inc.) in a buffer containing $50 \mathrm{mM} \mathrm{Na}_{3} \mathrm{PO}_{4}, 300 \mathrm{mM} \mathrm{NaCl}, 2 \mathrm{mM}$ imidazole, $\mathrm{pH}$ 8. Lysed cells were centrifuged at $\sim 27 \mathrm{k}$ RCF for 55 minutes to remove cellular debris. The lysate supernatant was then loaded onto a pre-charged $5 \mathrm{~mL} \mathrm{HiTrap} \mathrm{Ni-affinity}$ column (GE Healthcare) and the column was subsequently washed with lysis buffer. Following the lysis wash, the column was further washed with an increased imidazole buffer, $50 \mathrm{mM}$, and the protein was finally eluted using a linear gradient to $300 \mathrm{mM}$ imidazole. The eluted protein $(\sim 20 \mathrm{~mL})$ was diluted 7-fold in a buffer containing $20 \mathrm{mM}$ Tris and $2 \mathrm{mM}$ DTT, pH 8. This $\sim 175 \mathrm{~mL}$ solution was then loaded onto a $5 \mathrm{~mL}$ HiTrap Q column (GE Healthcare) and finally eluted using a steep linear gradient to $1 \mathrm{M} \mathrm{NaCl}$ in $20 \mathrm{mM}$ Tris, $2 \mathrm{mM}$ DTT, pH 8. The Q-fractions were analyzed for purity via SDS-PAGE and concentration concluded via $A_{280}$ absorbance, using molar extinction coefficients $\sim 25,900 \mathrm{M}^{-1} \mathrm{~cm}^{-1}$ and aliquots were subsequently stored at $-80^{\circ} \mathrm{C}$.

2.III.ii Casp-6 expression and purification - A similar procedure to casp-3 expression and purification was adapted here. pET 11a plasmid encoding constitutively two-chain (CT) human WT casp-6 was transformed into BL21(DE3) E.coli cells via electroporation. Single colony cultures were grown and the following day large LB cultures were inoculated with $\sim 3 \mathrm{~mL}$ per $\mathrm{L}$ of the small seed culture and grown at $37^{\circ} \mathrm{C}$ until an $\mathrm{OD}_{600}$ of $\sim 0.6$ was achieved. The incubation temperature was then reduced to $20^{\circ} \mathrm{C}$ and cells were induced with a final concentration of $1 \mathrm{mM}$ isopropyl $\beta$-D-1thiogalactopyranoside (IPTG) and left to express for $\sim 3$ hours. Cells were then harvested and frozen, cell pellets were then thawed and lysed using a microfluidizer (Microfluyidics, Inc.) in a buffer containing $50 \mathrm{mM}$ Tris, $300 \mathrm{mM} \mathrm{NaCl}, 5 \%$ glycerol, $2 \mathrm{mM}$ imidazole, $\mathrm{pH}$ 8.5. Lysed cells were centrifuged to remove cellular debris then loaded onto a pre-charged 5 $\mathrm{mL}$ HiTrap Ni-affinity column (GE Healthcare) and the column was subsequently washed with lysis buffer. Following the lysis wash, the column was further washed with an increased imidazole buffer, $50 \mathrm{mM}$, and the protein was finally eluted using a linear gradient to $300 \mathrm{mM}$ imidazole. The eluted protein $(\sim 20 \mathrm{~mL})$ was diluted 7 -fold in a buffer containing $20 \mathrm{mM}$ Tris, $5 \%$ glycerol and $2 \mathrm{mM}$ DTT, $\mathrm{pH} 8.5$. This $\sim 175 \mathrm{~mL}$ solution was then loaded onto a $5 \mathrm{~mL}$ HiTrap Q column (GE Healthcare) and finally eluted using a steep linear gradient to $1 \mathrm{M} \mathrm{NaCl}$ in $20 \mathrm{mM}$ Tris, $5 \%$ glycerol, $2 \mathrm{mM}$ DTT, pH 8.5. The Q-fractions were analyzed for purity via SDS-PAGE and concentration concluded via $A_{280}$ absorbance and aliquots were subsequently stored at $-80^{\circ} \mathrm{C}$.

2.III.iii Casp-7 expression and purification - A similar procedure to casp-3 expression and purification was adapted here. pET 23b plasmid encoding WT human casp-7 was transformed into BL21(DE3) E.coli cells via electroporation. Single colony cultures were grown and the following day large $2 x Y T$ cultures were inoculated with $\sim 5 \mathrm{~mL}$ per $\mathrm{L}$ of the small seed culture and grown at $37^{\circ} \mathrm{C}$ until an $\mathrm{OD}_{600}$ of $\sim 0.6$ was achieved. The incubation temperature was then reduced to $18^{\circ} \mathrm{C}$ and cells were induced with a final concentration of $1 \mathrm{mM}$ isopropyl $\beta$-D-1-thiogalactopyranoside (IPTG) and left to express for $\sim 18$ hours. Cells were then harvested and frozen, cell pellets were then thawed and lysed using a microfluidizer (Microfluyidics, Inc.) in a buffer containing $50 \mathrm{mM} \mathrm{Na}_{3} \mathrm{PO}_{4}, 300 \mathrm{mM} \mathrm{NaCl}, 2 \mathrm{mM}$ imidazole, pH 8. Lysed cells were centrifuged to remove cellular debris then loaded onto a pre-charged $5 \mathrm{~mL}$ HiTrap Ni-affinity column (GE Healthcare) and the column was subsequently washed with lysis buffer. Following the lysis wash, the column was further washed with an increased imidazole buffer, $50 \mathrm{mM}$, and the protein was finally eluted using a linear gradient to $300 \mathrm{mM}$ imidazole. The eluted protein $(\sim 20 \mathrm{~mL})$ was diluted 7-fold in a buffer containing $20 \mathrm{mM} \mathrm{Na}_{3} \mathrm{PO}_{4}, 2 \mathrm{mM}$ DTT, pH 8. This $\sim 175 \mathrm{~mL}$ solution was then loaded onto a $5 \mathrm{~mL}$ HiTrap Q column (GE Healthcare) and finally eluted using a steep linear gradient to $1 \mathrm{M} \mathrm{NaCl}$ in $20 \mathrm{mM}$ Tris, $2 \mathrm{mM}$ DTT, $\mathrm{pH}$ 8. The Q-fractions were analyzed for purity via SDS-PAGE and concentration concluded via $A_{280}$ absorbance and aliquots were subsequently stored at $-80^{\circ} \mathrm{C}$. Handcuffed casp- $7^{4}$ was purified similarly to WT casp-7.

2.III.iv Casp-8 expression and purification - A similar procedure to casp-3 expression and purification was adapted here. pET 15b plasmid encoding WT human casp-8 without the death-effector-domain domain (casp-8 $\Delta$ DED) was transformed into BL21(DE3) E.coli cells via electroporation. For significant casp-8 expression, it is essential that fresh transformation is executed. After colonies have developed, single colony cultures were immediately grown and the following day large $2 \times Y T$ cultures were inoculated with $\sim 5 \mathrm{~mL}$ per $\mathrm{L}$ of the small seed culture and grown at $37^{\circ} \mathrm{C}$ until an $\mathrm{OD}_{600}$ of $\sim 0.6$ was achieved. The incubation temperature was then reduced to $25^{\circ} \mathrm{C}$ and cells were induced with a final 
concentration of $1 \mathrm{mM}$ isopropyl $\beta$-D-1-thiogalactopyranoside (IPTG) and left to express for $\sim 3$ hours. Cells were then harvested and frozen, cell pellets were then thawed and lysed using a microfluidizer (Microfluyidics, Inc.) in a buffer containing $50 \mathrm{mM}$ Tris, $500 \mathrm{mM} \mathrm{NaCl}, 0.50 \%$ tween20, $2 \mathrm{mM}$ imidazole, $\mathrm{pH}$ 8. Lysed cells were centrifuged to remove cellular debris then loaded onto a pre-charged $5 \mathrm{~mL}$ HiTrap Ni-affinity column (GE Healthcare) and the column was subsequently washed with lysis buffer. Following the lysis wash, the column was further washed with an increased imidazole buffer, $20 \mathrm{mM}$, and the protein was finally eluted using a linear gradient to $300 \mathrm{mM}$ imidazole. The eluted protein $(\sim 20 \mathrm{~mL})$ was diluted 7-fold in a buffer containing $20 \mathrm{mM}$ Tris, $2 \mathrm{mM} \mathrm{DTT}$, pH 8. This $\sim 175 \mathrm{~mL}$ solution was then loaded onto a $5 \mathrm{~mL}$ HiTrap Q column (GE Healthcare) and finally eluted using a steep linear gradient to $1 \mathrm{M} \mathrm{NaCl}$ in 20 $\mathrm{mM}$ Tris, $2 \mathrm{mM}$ DTT, $\mathrm{pH}$ 8. The Q-fractions were analyzed for purity via SDS-PAGE and concentration concluded via $A_{280}$ absorbance and aliquots were subsequently stored at $-80^{\circ} \mathrm{C}$.

2.III.v Casp-9 expression and purification - A similar procedure to casp-3 expression and purification was adapted here but casp-9 protein was eluted in fractions from the Ni column and analyzed via SDS-PAGE prior to the $Q$ column. $p E T$ 23b plasmid encoding human WT casp-9 (or Casp-9cD) was transformed into BL21(DE3) E.coli cells via electroporation. Single colony cultures were grown and the following day large 2xYT cultures were inoculated with $\sim 4 \mathrm{~mL}$ per $\mathrm{L}$ of the small seed culture and grown at $37^{\circ} \mathrm{C}$ until an $\mathrm{OD}_{600}$ of $\sim 0.9$ was achieved. The incubation temperature was then reduced to $15^{\circ} \mathrm{C}$ and cells were induced with a final concentration of $1 \mathrm{mM}$ isopropyl $\beta$-D-1-thiogalactopyranoside (IPTG) and left to express for $\sim 3$ hours. Cells were then harvested and frozen, cell pellets were then thawed and lysed using a microfluidizer (Microfluyidics, Inc.) in a buffer containing $50 \mathrm{mM}$ Tris, $300 \mathrm{mM} \mathrm{NaCl}, 2 \mathrm{mM}$ imidazole, pH 8 . Lysed cells were centrifuged to remove cellular debris then loaded onto a pre-charged $5 \mathrm{~mL}$ HiTrap Ni-affinity column (GE Healthcare) and the column was subsequently washed with lysis buffer. Following the lysis wash (significant longer wash than the other caspases), the protein was eluted in fractions over a linear gradient to $100 \mathrm{mM}$ imidazole over $270 \mathrm{~mL}$ (casp-9 elutes over a significantly broad peak compared to other caspases). Fractions were analyzed via SDS-PAGE for purity and protein size. Fractions containing casp-9 protein were combined and diluted 7-fold in a buffer containing $20 \mathrm{mM}$ Tris, and $5 \mathrm{mM}$ DTT, pH 8.5. This casp-9 protein solution was then loaded onto a $5 \mathrm{~mL}$ HiTrap Q column (GE Healthcare) and finally eluted using a steep linear gradient to $1 \mathrm{M} \mathrm{NaCl}$ in $20 \mathrm{mM}$ Tris, $2 \mathrm{mM} \mathrm{DTT}$, pH 8.5. The Q-fractions were analyzed for purity via SDS-PAGE and concentration concluded via $A_{280}$ absorbance and aliquots were subsequently stored at $-80^{\circ} \mathrm{C}$.

2.IV Evaluation of caspase solvent exposed cysteines - As previously accomplished for casp- $3,{ }^{1}$ the number of solvent exposed cysteine residues can be measured using quantitative, colorimetric Ellman's reagent 5,5'-dithiobis-(2nitrobenzoic acid (DTNB). Since caspases are purified with DTT, the proteins were first buffer exchanged to remove the reducing agent and concentrations quantified using $A_{280}$ absorbance. Caspases were buffer exchanged to $20 \mathrm{mM}$ sodium phosphate, $100 \mathrm{mM} \mathrm{NaCl} \mathrm{pH} 7.5$ using 3K MWCO Amicon Filters or NAP5 (GE) column. A saturated, $50 \mathrm{mg} / \mathrm{mL}$, DTNB solution was made in the same buffer and prior to use, the insoluble DTNB was allowed to settle. A DTT standard curve was made by adding $10 \mu \mathrm{L}$ of the saturated DTNB solution to $50 \mu \mathrm{L}$ of DTT with concentrations ranging from $0-30 \mu \mathrm{M}$. Then, the various caspases were diluted and assayed similarly. Absorbance of each sample is monitored at $420 \mathrm{~nm}$ and caspase thiols were quantified from the DTT standard curve.

\section{V Casp-NG Characterization}

2.V.i Casp-NG protein release and encapsulation comparisons - Purified nanogels were removed from dialysis, volumes normalized and concentrations reevaluated. To visualize protein release, $30 \mu \mathrm{L}$ of the nanogel solution was incubated with either $10 \mu \mathrm{L}$ of $1 \mathrm{M}$ DTT or $1 \mathrm{X}$ PBS and left for 15 minutes at RT. $10 \mu \mathrm{L}$ of SDS-PAGE 3X dye (with reductant) was added to the DTT-NG sample and reductant free SDS-PAGE 3X dye was added to the water-NG sample. The samples were immediately boiled at $95^{\circ} \mathrm{C}$ for $\sim 5$ minutes and then added to a $16 \%$ SDS-PAGE and electrophoresis was executed at $175 \mathrm{~V}$ for 60 minutes. To compare encapsulation efficiencies, only when ran on the same gel, large subunit band intensities of all casp-NG released proteins were compared to casp-3 using Image Lab ${ }^{\mathrm{TM}}$ Software.

2.V.ii Casp-NG size evaluation - Purified nanogels were diluted to $\sim 0.5-1 \mathrm{mg} / \mathrm{mL}$ in water and subsequently filtered to remove dust using a $0.45 \mu \mathrm{m}$ syringe filter. After filtration, samples were subjected to DLS characterization using a Malvern Nanozetasizer operating at $633 \mathrm{~nm}$. For each sample, three readings with 10 runs each were run.

2.V.ii Cy5-Casp labeling, nanogel formation and uptake study - Full length, catalytically inactive versions of all caspase variants (Casp-3 C163A, Casp-6 C163A, Casp-7 C186A, Casp-8 C360A and Casp-9 C287A) were diluted to 32 $\mu \mathrm{M}$ in $0.1 \mathrm{M} \mathrm{NaHCO} 3, \mathrm{pH} 8.5$ to protonate all lysine residues. To these solutions, 1.5 equivalents of Cy5-NHS ester (approximately $0.4 \mathrm{mg}$ ) was added in 10\% DMSO of the final reaction volume. These solutions were left to react for 3 hours at room temperature. Free dye was removed via purification using NAP5 columns (GE Healthcare) before NG formation on the same day, NG prepared as previously described. As all caspases were fluorescently labeled to different extents, the final uptake data was normalized to the highest NG dose (see supplemental figure). The day of protein labeling and NG formation, HEK293T cells were seeded at a density of $\sim 5 \times 10^{4}$ in a 24-well plate and left to adhere for 
$\sim 24$ hours. The next day, media was removed and purified NG samples added in a media and 1X PBS, pH 7.4 mixture where the 1X PBS composes $10 \%$ of the final solution volume. Samples were left to incubate for 6 hours before flow cytometry analysis. Notably, all caspases demonstrated different extents of fluorescent labeling. Accordingly, after selecting the live, single cell population, the mean fluorescence intensity for the highest dose was normalized to $100 \%$ for each casp-NG. The subsequent doses $(0.5 \mathrm{mg} / \mathrm{mL}, 0.25 \mathrm{mg} / \mathrm{mL})$ were quantified based on the maximum $1 \mathrm{mg} / \mathrm{mL}$ dose. 


\section{Supplemental Figures (S\#)}

Figure S1. Approximate apoptotic caspase NG encapsulation efficiencies. Quantification of released caspase large subunit band intensity reveals similar encapsulation across all caspase cargos. Error bars correspond to SEM of at least two independent NG batches, made and tested on separate days.
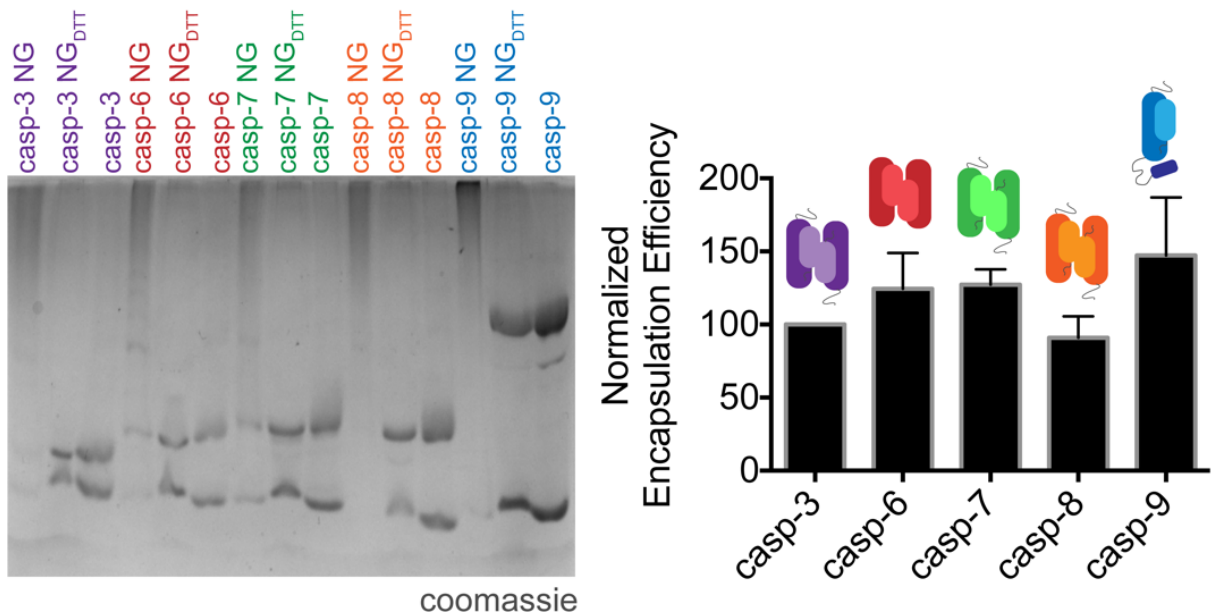

Figure S2. Casp-9 $9_{\mathrm{CD}}$ encapsulation and release. Casp- $9_{\mathrm{CD}}$ was prepared using site directed mutagenesis, replacing five residues in casp-9 (Gly402-Cys-Phe-Asn-Phe406) with those in casp-3 (Cys264-Ile-Val-Ser-Met268). ${ }^{5}$ Casp-9cD was effectively encapsulated and released from PEG-PDS NG. The amount of casp- $9_{\mathrm{CD}}$ encapsulated is similar to WT casp-9 (88-94\% after normalizing to WT casp-9 large subunit), error bars correspond to SEM of two independent NG batches, made and tested on separate days.

constitutive dimer (cD) casp-9

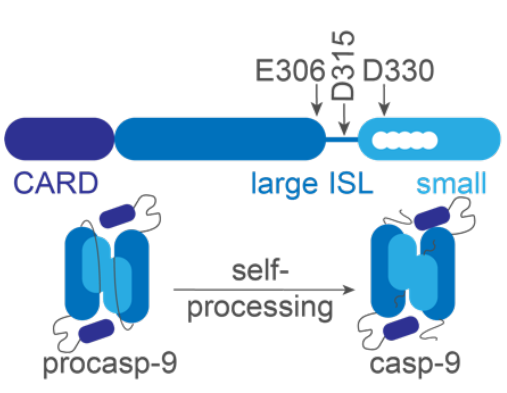

white circles depict five mutations in the $\beta 6$ strand of casp- 9
NG encapsulation \& release

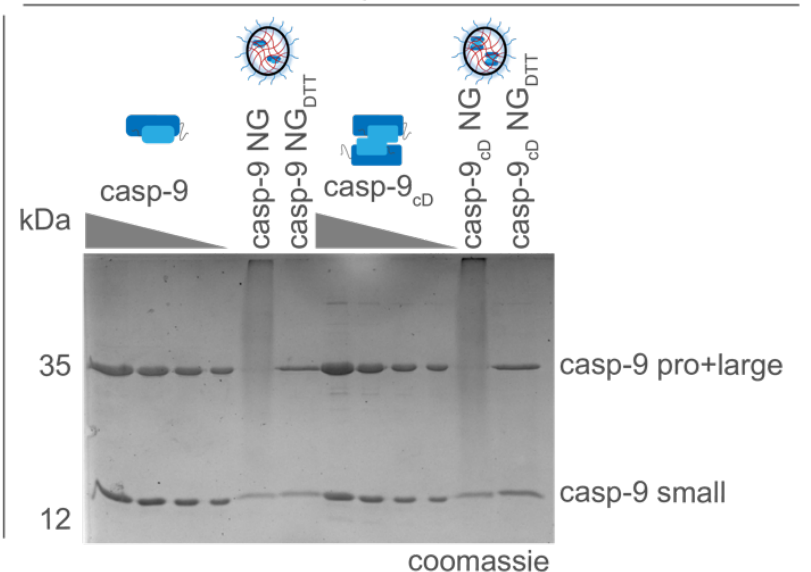

encapsulation efficiency

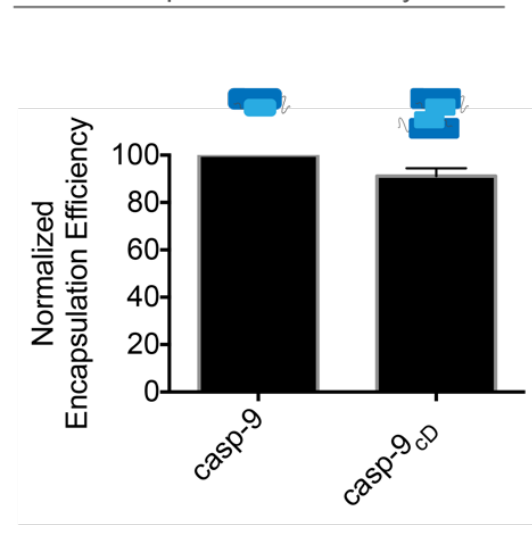


Figure S3. NG-released caspase activity in lysates workflow. Proteins were kept encapsulated or released (+DTT) before addition of cell lysate and subsequent analysis of substrate proteolysis by western blot.

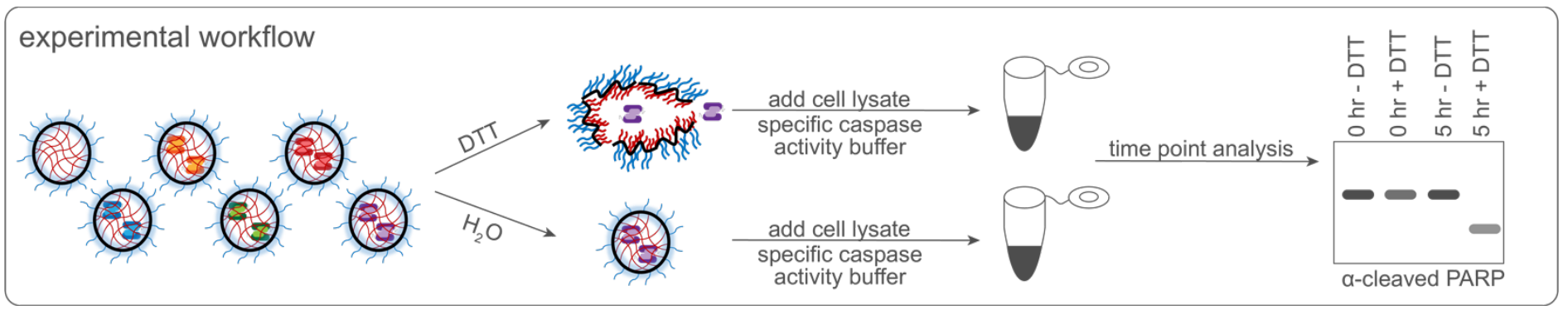

Figure S4. Delivery of Cy5-labelled apoptotic caspase monitored by flow cytometry. (A) Experimental schematic. (B) NG crosslinking (343 nm) and visualization of different extents of Cy5- labeling (633 nm). (C) Dose dependent example of Cy5-casp-7 NG delivery. (D) Normalized uptake of all casp-NG demonstrate dose dependent delivery.
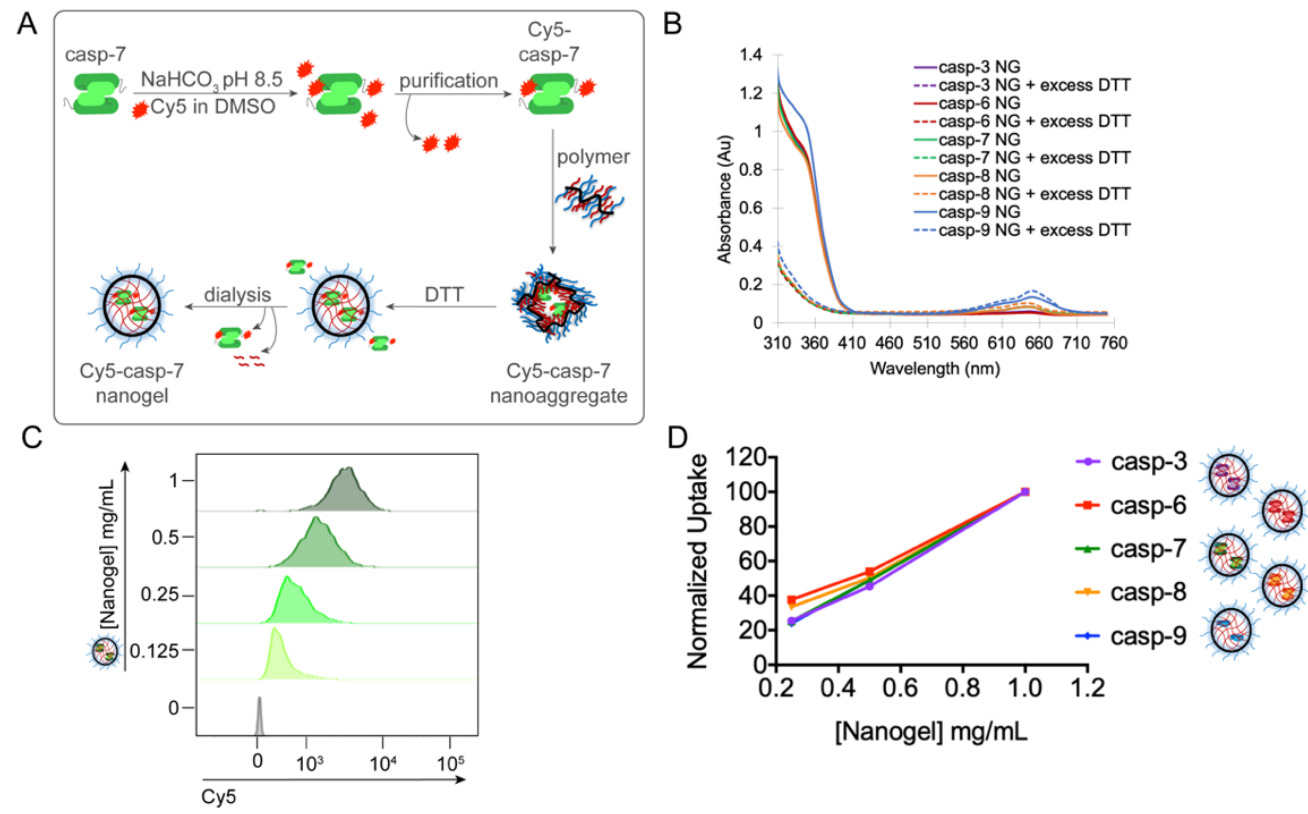

Figure S5. Casp-8 delivery to different cell lines. The amount of casp-8 protein delivered was quantified by normalizing casp-8 small to alpha tubulin.

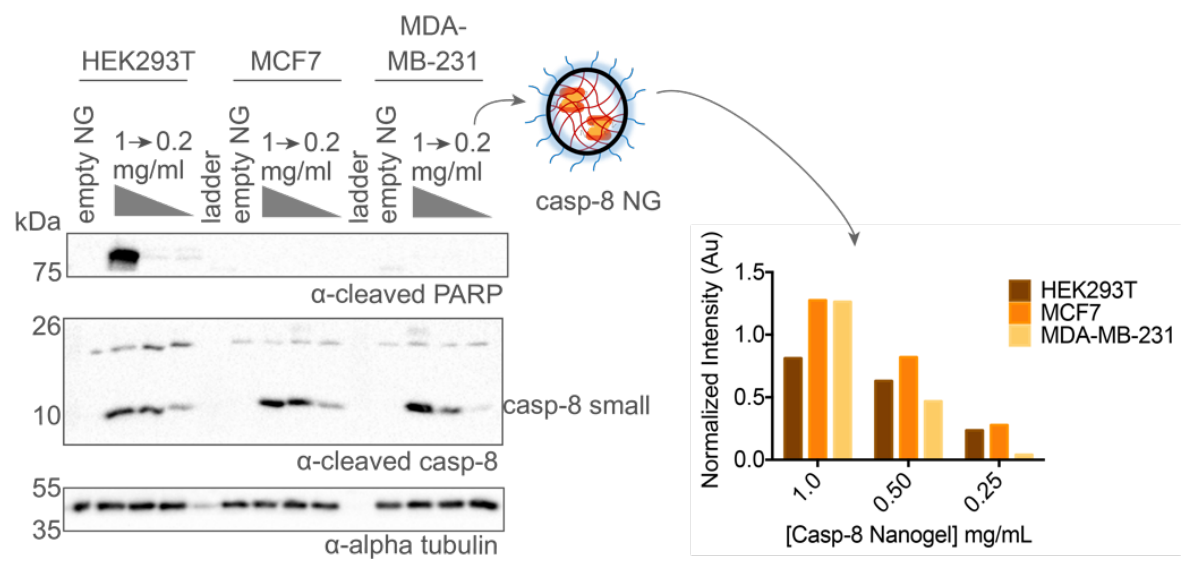


Figure S6. Workflow for apoptosis evaluation using 7-AAD. Workflow adapted from literature. ${ }^{6,7}$
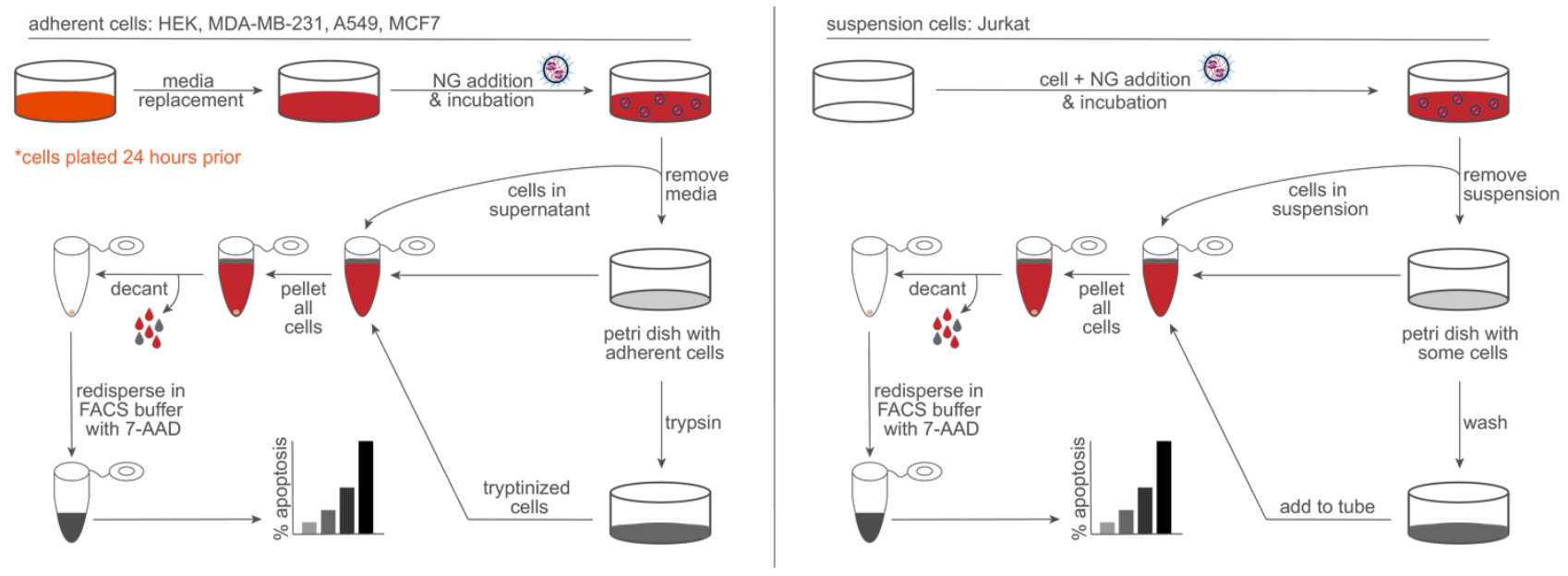

Figure S7. Casp-9cD NG induced cell death. Left: Casp-9 $9_{\mathrm{cD}}$ NG induced 1.76X more apoptosis compared to casp-9 cargo (five independent NG batches normalized to casp-9 induced apoptosis, in HEK293T cells). Right: AnnexinV assay also demonstrated more apoptosis by the constitutive dimeric $(\mathrm{CD})$ cargo.
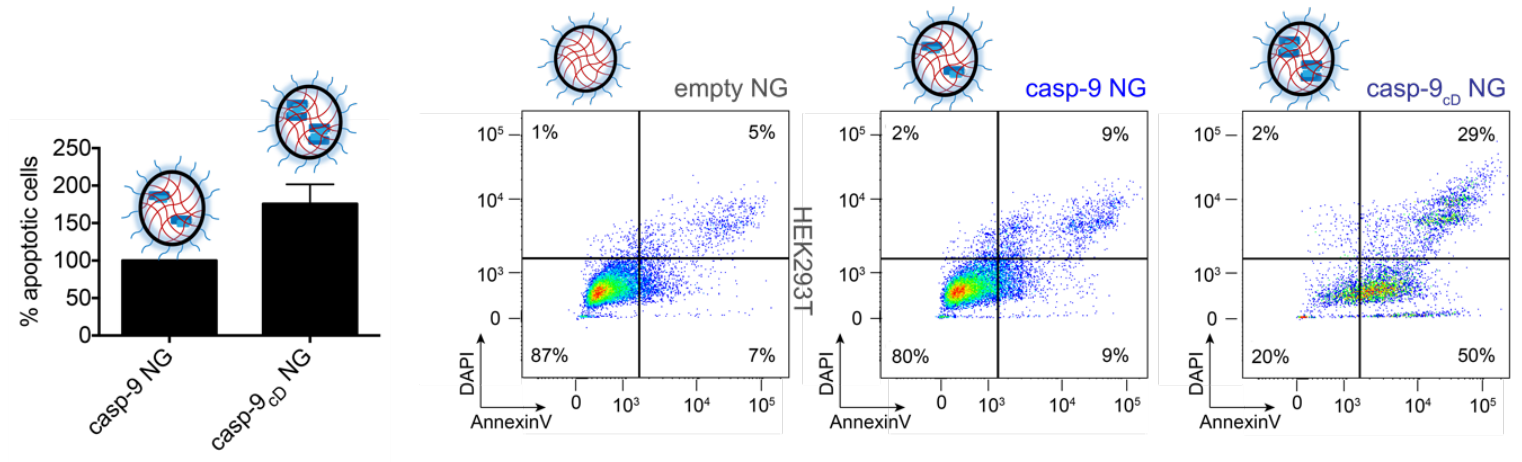

Figure S8. Handcuffed casp-7 PEG-PDS NG. (A) NG encapsulation and release of handcuffed casp-7 (casp-7 $\left.7_{\mathrm{HC}}\right)^{4}$ in

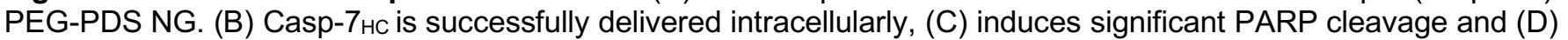
apoptotic cell death (error bars represent SEM of two biological replicates, independent NG batches made and tested on separate days).
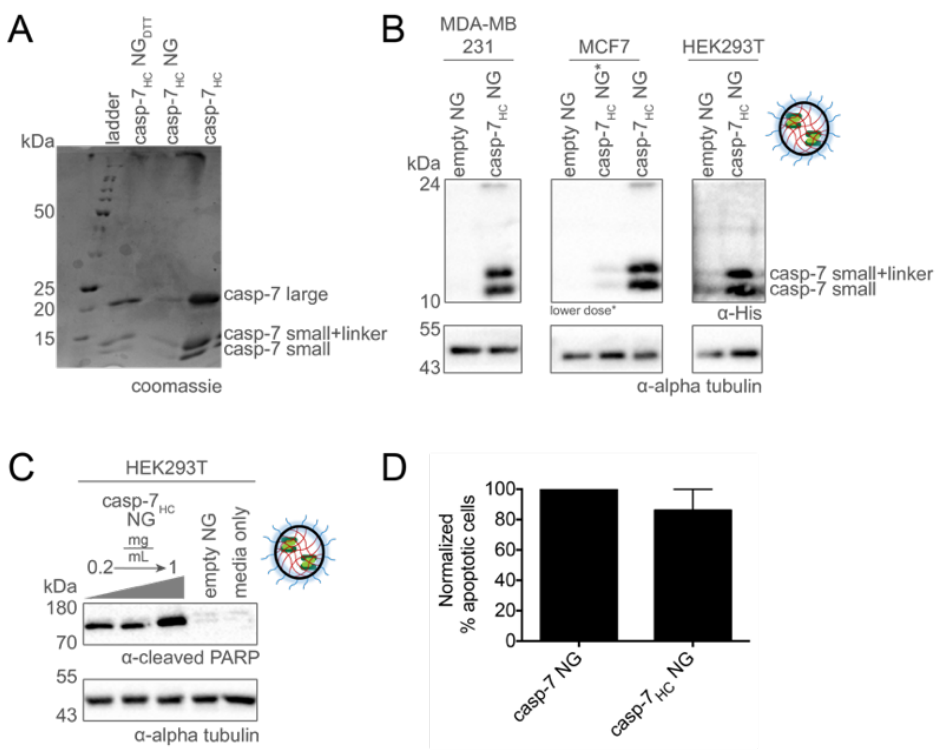
Figure S9. Workflows for evaluating executioner caspase activity in whole or lysed cells. Top: Workflow for detection of caspase activity toward multiple fluorogenic peptide substrates in whole cells after treatment with various casp-NG. Bottom: Workflow for detection of caspase activity toward multiple fluorogenic peptide substrates in lysed cells, with DTT added, after treatment with various casp-NG indicating casp-NG have been significantly delivered intracellularly but are trapped in endosomes.

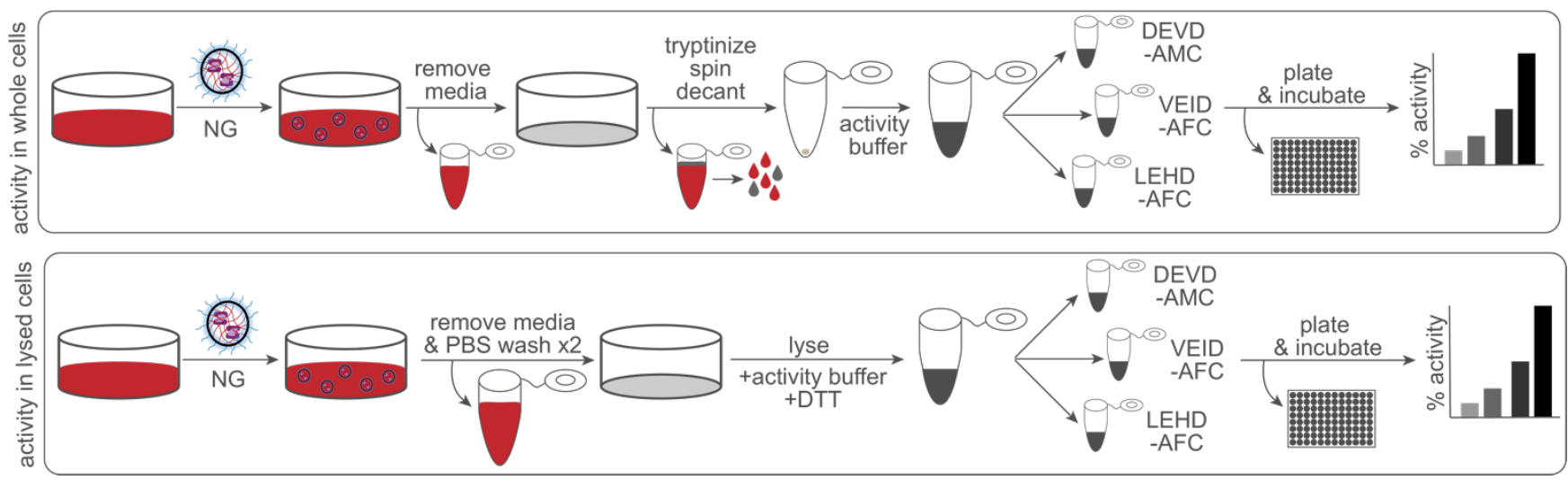

Figure S10. Executioner caspase activity in whole cells, with or without DTT. Similar experiment to Figure 8A, but with DTT added (i.e. activity of intracellular exogenous executioner caspases towards different fluorogenic substrates in cells, with DTT present). Bars plotted are one biological replicate in duplicate.
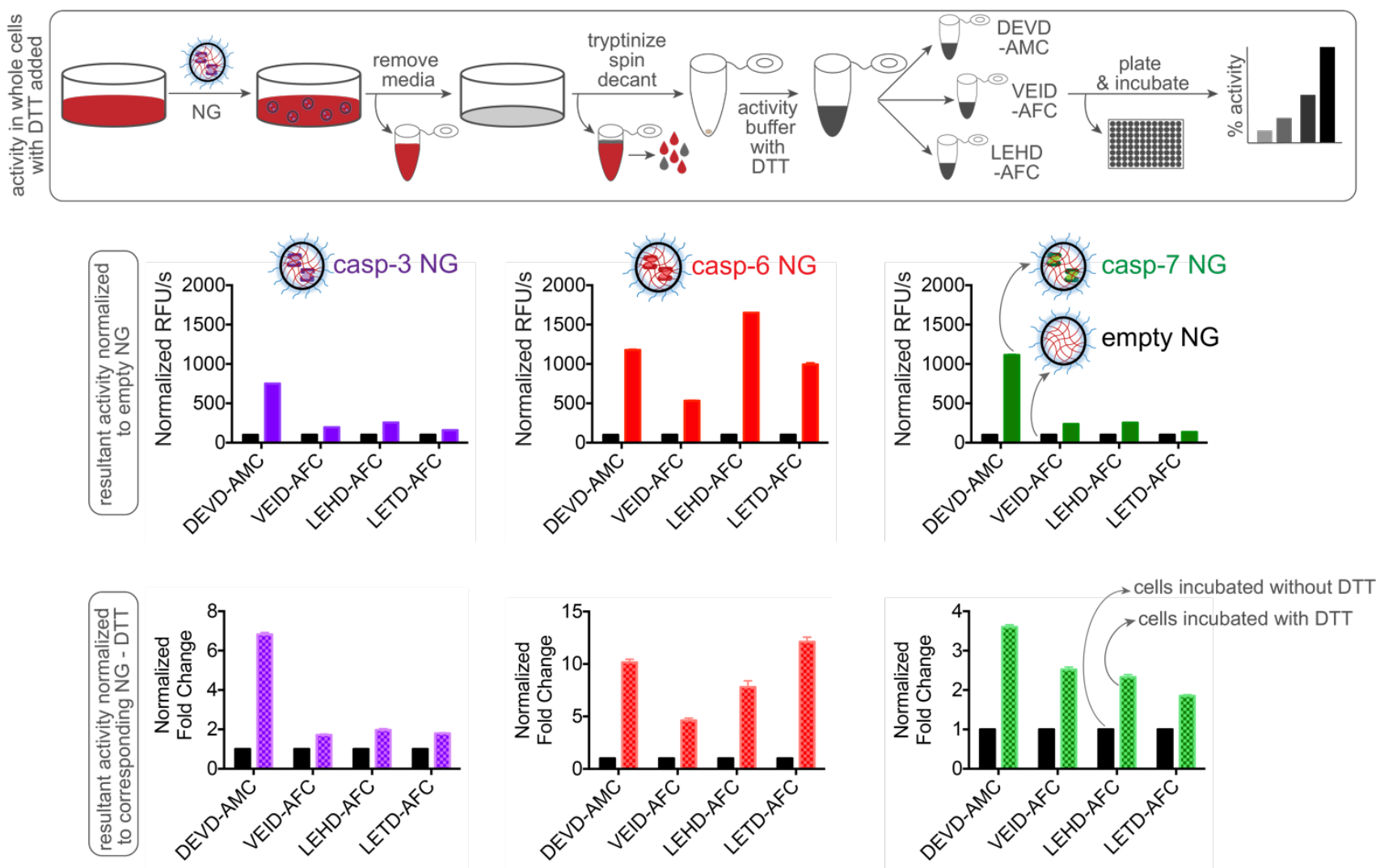
Figure S11. Executioner caspase activity in cell lysates. Data from Figure $8 \mathrm{E}-\mathrm{H}$, plotted as a function of time. Error bars pertain to technical replicates, experiment was executed in biological triplicate.
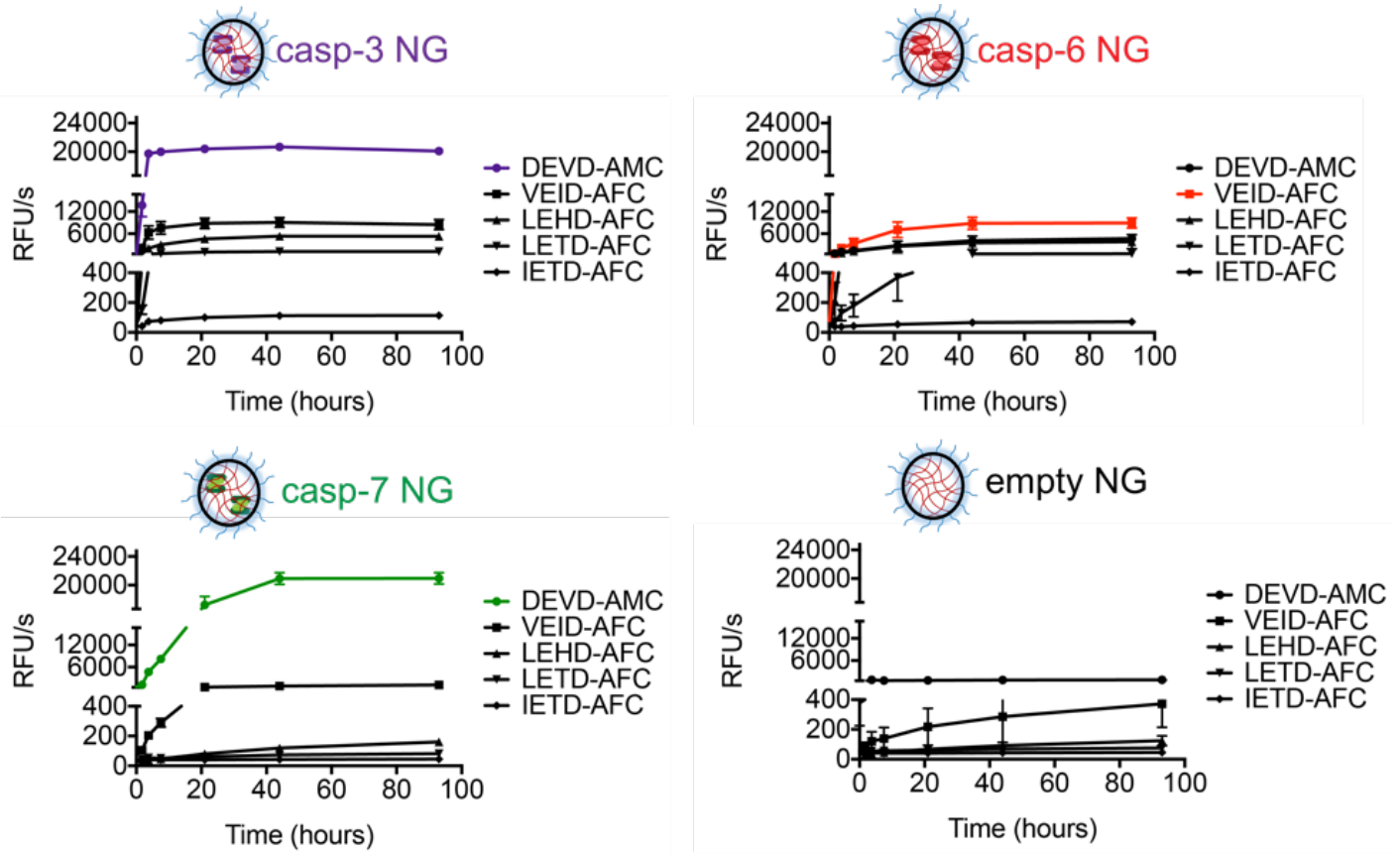


\section{Supplemental Scheme}

\section{Scheme S1. Known caspase-procaspase activation and substrate cleavage.}

Top panel: Casp-8 and casp-9 are activated in response to extrinsic or intrinsic stimuli, respectively. These initiator caspases then activate the executioner casp-3, -6 and -7 , facilitating substrate cleavage and apoptosis propagation. Bottom panel: Reported possibilities of executioner casp-3, -6, -7 procaspase cleavage. Caspase enzymes are color coded consistently with Figure 1 and their corresponding substrates for clarity: casp-3 (purple), casp-6 (red), casp-7 (green), casp-8 (orange), casp-9 (blue).

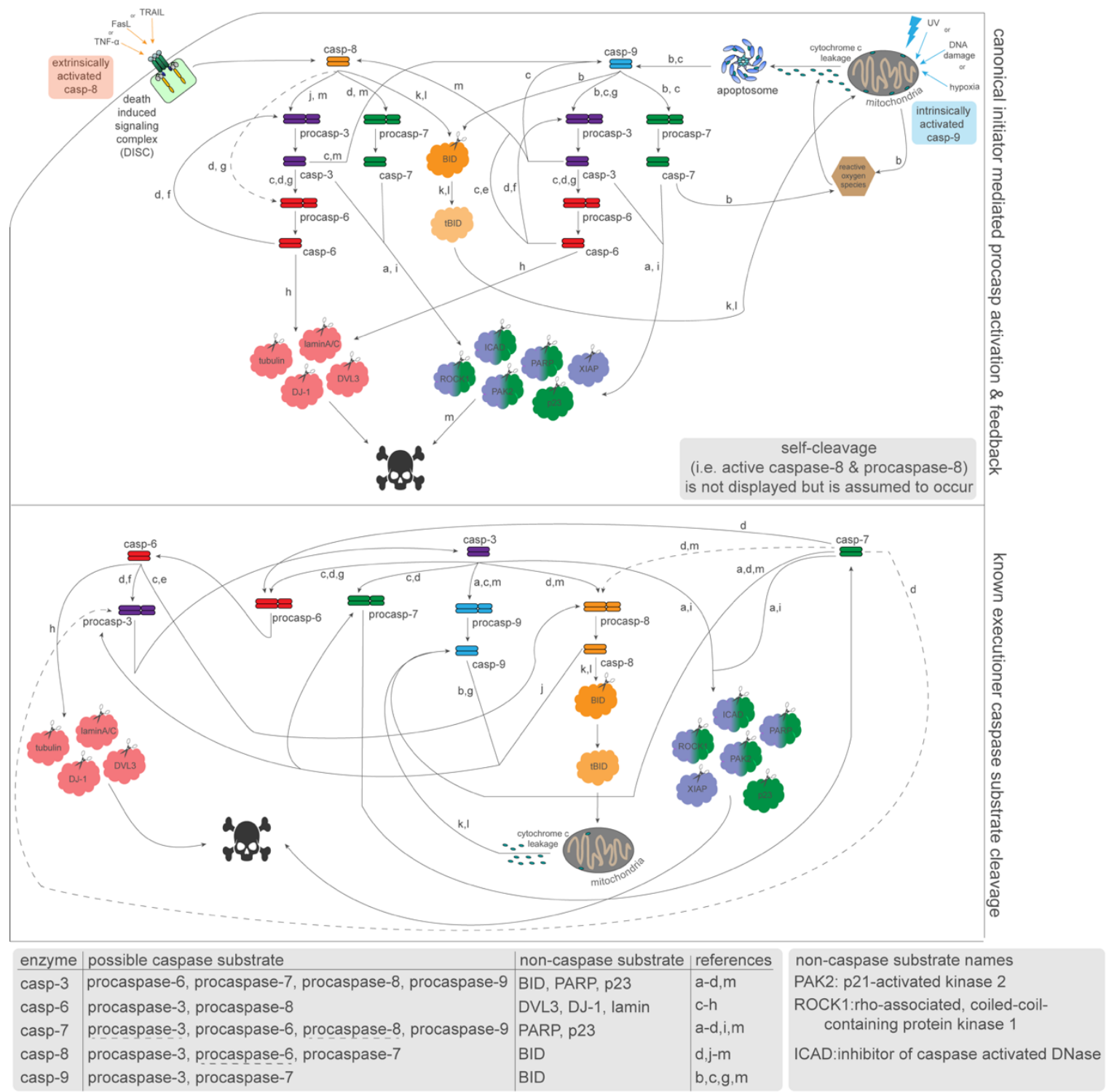

aExecutioner caspase-3 and caspase-7 are functionally distinct proteases. PNAS (2008) 105, 12815-12819

${ }^{\circ}$ Caspase-9, caspase-3 and caspase-7 have distinct roles during intrinsic apoptosis. BMC Cell Biology (2013) 14, 32.

COrdering the Cytochrome C-initiated Caspase Cascade: Hierarchical Activation of Casp-2, -3, -6, -7, -8, and -10 in a Casp-9-dependent Manner. JCB (1999) 144, 281-292. ${ }^{\top}$ The proteolytic procaspase activation network: an in vitro analysis. Cell Death and Differentiation (1999) 6, 1117 - 1124.

${ }^{\circ}$ Caspase- 6 is the direct activator of caspase-8 in the cytochrome c-induced apoptosis pathway. Cell Death and Differentiation (2002) 9, 1046 - 1056

'Caspase-6 activity initiates caspase-3 activation in cerebellar granule cell apoptosis. Cell Death and Differentiation (2000) 7, $984 \pm 993$.

${ }^{9} \mathrm{~A}$ caspase cascade regulating developmental axon degeneration. The Journal of Neuroscience (2012) 32,17540 -17553.

"Tri-arginine exosite patch of caspase-6 recruits substrates for hydrolysis. JBC (2019) 294, 71-88.

Caspase-7 uses RNA to enhance proteolysis of poly(ADP-ribose) polymerase 1 and other RNA-binding proteins. PNAS (2019) 116, 21521-21528.

Pro-caspase-3 is a major physiologic target of caspase-8. JBC (1998) 273, 27084-27090.

kCaspase-8 and Bid: Caught in the act between death receptors and mitochondria. Biochimica et Biophysica Acta 1813 (2011) 558-563.

'Cleavage of BID by Caspase 8 Mediates the Mitochondrial Damage in the Fas Pathway of Apoptosis. Cell (1998) 94, 491-501.

${ }^{m}$ Efficient apoptosis requires feedback amplification of upstream apoptotic signals by effector caspase-3 or -7. Sci. Adv. (2019), 5, 1-11. 


\section{Supplemental Tables:}

\section{Supplemental Table S1. Kinetic Parameters for caspase variants.}

\begin{tabular}{|l|l|l|l|l|l|} 
caspase & description & $\mathrm{K}_{\mathrm{m}}(\mu \mathrm{M})$ & $\mathrm{k}_{\text {cat }}\left(\mathrm{s}^{-1}\right)$ & $\mathrm{k}_{\text {cat }} / \mathrm{K}_{\mathrm{m}}\left(\mu \mathrm{M} / \mathrm{s}^{-1}\right)$ & reference \\
\hline casp-3 & executioner & 10 & 14 & 1.4 & $\mathrm{a}$ \\
casp-6 & executioner & 38 & 0.7 & 0.02 & $\mathrm{~b}$ \\
casp-7 & executioner & 41 & 2.4 & 0.06 & $\mathrm{~b}, \mathrm{c}$ \\
casp-7 & handcuffed casp-7 & 39 & 2.4 & 0.06 & $\mathrm{c}$ \\
casp-8 & extrinsic initiatior & 7 & 0.4 & 0.05 & $\mathrm{a}$ \\
casp-9 & intrinsic initiator & 430 & 1.4 & 0.003 & $\mathrm{~d}$ \\
\hline
\end{tabular}

${ }^{a}$ N. Thornberry et al. Cell Death and Differentiation. 1999, 6, 362 - 369.

${ }^{b}$ M. Hill, D. Macpherson et al. and J.A. Hardy. ACS Chem Biol. 2016,11(6),1603-1612.

'Witkowski, W. A. and J.A. Hardy. Protein Science. 2011. 20, 1421-1431.

${ }^{d}$ B.P. Serrano et al. and J.A. Hardy. J Biol Chem. 2017, 292(52), 21352-21365.

\section{Supplemental Table S2. Casp-3, -7 methods of inhibition.}

\begin{tabular}{|c|c|c|}
\hline intracellular inhibition & casp-3 & casp-7 \\
\hline prosurvival antagonists & IAPs ${ }^{a-c}:$ XIAP, clAPs & IAPs ${ }^{a-c}:$ XIAP, clAPs \\
\hline phosphorylation & p38-MAPK (S150) d & PAK2 (S239) \\
\hline metal binding $(\mathrm{Zn})$ & $7 \mathrm{nM}(\text { three } \mathrm{Zn})^{\mathrm{f}}$ & $76 \mathrm{nM}(\text { one } \mathrm{Zn})^{\mathrm{f}}$ \\
\hline S-nitrosylation & $85 \%$ of mitochondrial casp-3 $(\mathrm{C} 163 \mathrm{~S})^{\mathrm{g}}$ & $\mathrm{NO}^{\mathrm{h}}$ \\
\hline glutathionylation & C163, C220i & \\
\hline phosphorylation & CK2 (ISL T174,S176) ${ }^{\mathrm{d}}$ & PAK2 (S30) \\
\hline
\end{tabular}

aSalvesen, G. S. and Duckett, C. S. IAP Proteins: Blocking The Road To Death's Door. Nature Reviews Molecular and Cellular Biology 2002, 3, $401-405$.

'Suzuki, Y. and Takahashi, R. et al. X-linked Inhibitor of Apoptosis Protein (XIAP) Inhibits Casp-3 and -7 in Distinct Modes. JBC 2001, 276 (29), $27058-27063$.

${ }^{\circ}$ Choi, Y. E. and Bratton, S. B. et al. The E4 Ubiquitin Ligase clAP1 Binds \& Ubiquitinates Casp-3 \& Casp-7 via Unique Mechanisms at Distinct Steps in Their Processing. JBC 2009, 284 (19), 12772-12782. ${ }^{-}$Thomas, M.E., Clark, A. C. et al. Modifications to a common phosphorylation network provide individualized control in caspases. JBC, $2018,293,5447-5461$.

eEron, S.J., Raghupathi, K.. Hardy, J.A. Dual Site Phosphorylation of Caspase-7 by PAK2 Blocks Antiapoptotic Activity By Two Distinct Mechanisms. Structure, 2017, 25, 27-39.

'Eron, S.J., MacPherson, D.J., Hardy, J.A. Multiple Mechanisms of Zinc-Mediated Inhibition for the Apoptotic Caspases-3, -6, -7 and -8. ACS Chem. Biol., 2018,13, 1279-1290.

${ }^{9}$ Mannick, J.B. and Gaston, B. et al. S-Nitrosylation of mitochondrial caspases. JBC, 2001, 154,1111-1116.

${ }^{\mathrm{L}} \mathrm{Li}$, J. et al. and Kim, Y. M. Nitric Oxide Reversibly Inhibits Seven Members of the Caspase Family via S-Nitrosylation. Biochem Biophys Res Commun, 1997, 240, 419-424.

'Huang, Z. and John, P. R. et al. Inhibition of Caspase-3 Activity and Activation by Protein Glutathionylation. Biochem Pharmacol, 2008, 75, 2234-2244.

\section{Supplemental Table S3. Summary of apoptotic casp-NG results}

\begin{tabular}{|c|c|c|c|c|c|c|c|c|}
\hline & & casp-3 & casp-6 & casp-7 & casp-8 & casp-9 & casp-9 $9_{\mathrm{CD}}$ & \\
\hline & NG formation & $\checkmark$ & $\checkmark$ & $\checkmark$ & $\checkmark$ & $\checkmark$ & $\checkmark$ & Figure $2, \mathrm{~S} 1, \mathrm{~S} 2$ \\
\hline 永 & peptide sub. & $80 \%$ & $256 \%$ & $162 \%$ & $7 \%$ & $6 \%$ & $36 \%$ & Figure 3 \\
\hline 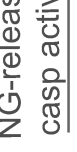 & protein sub. & $\begin{array}{l}\text { PARP } \\
\text { procasp-6 } \\
\text { p23 }\end{array}$ & $\begin{array}{l}\text { DVL3 } \\
\operatorname{laminA} \\
\text { DJ-1 }\end{array}$ & $\begin{array}{l}\text { PARP } \\
\text { procasp-3 } \\
\text { p23 }\end{array}$ & $\begin{array}{l}\text { BID } \\
\text { procasp-3 } \\
\text { PARP }\end{array}$ & $3^{\text {PARP }}$ & PARP & Figure 4 \\
\hline$\stackrel{\leftarrow}{m}$ & delivery & $\checkmark$ & $\checkmark$ & $\checkmark$ & $\checkmark$ & $\checkmark$ & $\checkmark$ & Figure 5, S4,S5 \\
\hline ָे. & PARP cleav. & $\checkmark$ & $\checkmark$ & $\checkmark$ & - & $\checkmark$ & $\checkmark$ & Figure 6 \\
\hline 立 & $\begin{array}{l}\text { apoptosis } \\
\text { *normalized to casp-3 }\end{array}$ & $1.0 x$ & $1.0 x$ & $1.7 x$ & $<0.2 x$ & $1.2 x$ & $2.1 x$ & Figure 7 \\
\hline$\frac{\frac{i}{\pi}}{\frac{\pi}{2}}$ & 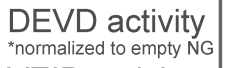 & $1.8 x$ & $1.2 x$ & $9.8 x$ & $1.0 x$ & $1.1 \mathrm{x}$ & $1.5 x$ & Figure $8_{\text {casp-3,-6,-7 }}$ \\
\hline$\overline{\bar{\Phi}}$ & $\begin{array}{l}\text { VEID activity } \\
{ }^{*} \text { normalized to empty NG }\end{array}$ & $2.0 x$ & $2.2 x$ & $2.2 x$ & $1.2 x$ & $1.2 x$ & $1.3 x$ & Figure $8_{\text {casp-3,-6,-7 }}$ \\
\hline 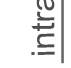 & $\begin{array}{l}\text { LEHD activity } \\
\text { *normalized to empty NG }\end{array}$ & $2.3 x$ & $5.0 x$ & $2.1 x$ & $1.2 x$ & $1.4 x$ & $1.7 x$ & Figure $8_{\text {casp-3,-6,-7 }}$ \\
\hline
\end{tabular}

DEVD recognition sequence of casp-3,-7; VEID of casp-6; LEHD of casp-8, -9 


\section{Supplemental References:}

(1) Ventura, J.; Eron, S. J.; González-Toro, D. C.; Raghupathi, K.; Wang, F.; Hardy, J. A.; Thayumanavan, S. Reactive Self-Assembly of Polymers and Proteins to Reversibly Silence a Killer Protein. Biomacromolecules 2015, 10, 3161-3171.

(2) Ghosh, S.; Basu, S.; Thayumanavan, S. Simultaneous and Reversible Functionalization of Copolymers for Biological Applications. Macromolecules 2006, 17, 5595-5597.

(3) Perry, D. K.; Smyth, M. J.; Stennicke, H. R.; Salvesen, G. S.; Duriez, P.; Poirier, G. G.; Hannun, Y. A. Zinc Is a Potent Inhibitor of the Apoptotic Protease, Caspase-3. J. Biol. Chem. 1997, 30, 18530-18533.

(4) Witkowski, W. A.; Hardy, J. A. A Designed Redox-Controlled Caspase. 2011, 20, 1421-1431.

(5) Chao, Y.; Shiozaki, E. N.; Srinivasula, S. M.; Rigotti, D. J.; Fairman, R.; Shi, Y. Engineering a Dimeric Caspase-9: A Re-Evaluation of the Induced Proximity Model for Caspase Activation. PLoS Biol. 2005, 6, 1079-1087.

(6) Zembruski, N. C. L.; Stache, V.; Haefeli, W. E.; Weiss, J. 7-Aminoactinomycin D for Apoptosis Staining in Flow Cytometry. Anal. Biochem. 2012, 1, 79-81.

(7) Lecoeur, H.; De Oliveira-Pinto, L. M.; Gougeon, M. L. Multiparametric Flow Cytometric Analysis of Biochemical and Functional Events Associated with Apoptosis and Oncosis Using the 7-Aminoactinomycin D Assay. J. Immunol. Methods 2002, 265, 81-96. 